\title{
Mice Lacking Major Brain Gangliosides Develop Parkinsonism
}

\author{
Gusheng Wu $\cdot$ Zi-Hua Lu $\cdot$ Neil Kulkarni $\cdot$ \\ Ruchi Amin • Robert W. Ledeen
}

Accepted: 24 February 2011 / Published online: 12 March 2011

(C) The Author(s) 2011. This article is published with open access at Springerlink.com

\begin{abstract}
Parkinson's disease (PD) is the second most prevalent late-onset neurodegenerative disorder that affects nearly $1 \%$ of the global population aged 65 and older. Whereas palliative treatments are in use, the goal of blocking progression of motor and cognitive disability remains unfulfilled. A better understanding of the basic pathophysiological mechanisms underlying PD would help to advance that goal. The present study provides evidence that brain ganglioside abnormality, in particular GM1, may be involved. This is based on use of the genetically altered mice with disrupted gene Galgt1 for GM2/GD2 synthase which depletes GM2/GD2 and all the gangliotetraose gangliosides that constitute the major molecular species of brain. These knockout mice show overt motor disability on aging and clear indications of motor impairment with appropriate testing at an earlier age. This disability was rectified by L-dopa administration. These mice show other characteristic symptoms of PD, including depletion of striatal dopamine (DA), loss of DA neurons of the substantia nigra pars compacta, and aggregation of alpha synuclein. These manifestations of parkinsonism were largely attenuated by administration of LIGA-20, a membrane permeable analog of GM1 that penetrates the blood brain barrier and enters living neurons. These results suggest that perturbation of intracellular mechanisms mediated by intracellular GM1 may be a contributing factor to PD.
\end{abstract}

Special Issue: In Honor Dr. Robert Yu.

G. Wu ( $\square)$ · Z.-H. Lu · N. Kulkarni · R. Amin · R. W. Ledeen Department of Neurology and Neurosciences, New Jersey Medical School, UMDNJ, 185 So. Orange Ave., MSB-H506, Newark, NJ 07103, USA

e-mail: ledeenro@umdnj.edu
Keywords Parkinson's disease · GM1 ganglioside · LIGA-20 · Dopaminergic neurons · Alpha synuclein

$\begin{array}{ll}\text { Abbreviations } \\ \text { Ab } & \text { antibody } \\ \text { a-syn } & \text { alpha-synuclein } \\ \text { BSS } & \text { balanced salt solution } \\ \text { CtxB } & \text { B subunit of cholera toxin } \\ \text { DA } & \text { dopamine or dopaminergic } \\ \text { DOA } & \text { days of age } \\ \text { DOPAC } & \text { dihydroxyphenyl acetic acid } \\ \text { ER } & \text { endoplasmic reticulum } \\ \text { HRP } & \text { horseradish peroxidase } \\ \text { 5-HT } & \text { 5-hydroxytryptamine (serotonin) } \\ \text { 5-HIAA } & \text { 5-hydroxyindole acetic acid } \\ \text { IP } & \text { intraperitoneally } \\ \text { KO } & \text { knockout } \\ \text { MPTP } & \text { 1-methyl-4-phenyl-1,2,3,6-tetrahydropyridine } \\ \text { PBS } & \text { phosphate buffered saline } \\ \text { PD } & \text { Parkinson's disease } \\ \text { SNpc } & \text { substantia nigra pars compacta } \\ \text { TH } & \text { tyrosine hydroxylase } \\ \text { VTA } & \text { ventral tegmental area } \\ \text { WT } & \text { wild type }\end{array}$

\section{Introduction}

Gangliosides are well recognized mediators of certain essential signaling pathways in the nervous system and other organs [1], and a growing number of proteins involved in such pathways are seen to function in association with one or another ganglioside. Considerable insight into ganglioside-protein interactions has been gained from 
a study of animals with mutated genes required for ganglioside biosynthesis. One of the most studied is a mouse with disrupted gene Galgt1 which encodes the enzyme UDP-GalNAc:lactosylceramide/GM3/GD3 $\quad \beta$-1,4-N-acetylgalactosaminyltransferase (GM2/GD2 synthase; GalNAcT; EC 2.4.1.92). This mutation results in elimination of GM2 and GM1 along with other members of the gangliotetraose family which compromise $>90 \%$ of CNS gangliosides. Such mice suffer a slight reduction in neural conduction velocity [2] in addition to decreased central myelination and axonal degeneration [3]. They also show progressive behavioral neuropathies including deficits in reflexes, strength coordination and balance [4]. At the cellular level, cultured neurons from such mice were found deficient in $\mathrm{Ca}^{2+}$ regulation as reflected in vitro by degeneration in the presence of depolarizing levels of $\mathrm{K}^{+}$ [5] and in vivo by enhanced susceptibility to kainateinduced seizures [6].

The present study has probed further into the movement disorder and pathophysiological manifestations of such knockout (KO) mice and found a constellation of symptoms strongly representative of Parkinson's disease (PD). A primary neuropathological feature of the sporadic form of PD is the substantial depletion of dopaminergic (DA) neurons in the substantia nigra pars compacta ( $\mathrm{SNpc}$ ), although loss of other neuronal types can also occur prior or subsequent to that in the SNpc [7]. In addition to accompanying decrease of dopamine (DA) in SNpc and striatum, a prominent neuropathological feature is accumulation of alpha-synuclein (a-syn) within cytoplasmic inclusions termed Lewy bodies. In contrast to the much rarer familial cases, which show generally similar neuropathology, the etiology of sporadic PD is not well understood as reflected in the several theories that have been proposed. Most of these are based on a variety of interactions between environmental factors and genetic predisposition.

Rodents subjected to neurotoxins have been widely used to model some of the key features of $\mathrm{PD}$, the most prominent being 1-methyl-4-phenyl-1,2,3,6-tetrahydropyridine (MPTP), 6-hydroxy dopamine, rotenone, and paraquat [8]. The above mentioned GalNAcT ${ }^{-1-} \mathrm{KO}$ mouse has the advantage as a model in its spontaneous acquisition of parkinsonian symptoms, thus avoiding the potentially confounding influence of extraneous toxins. The present study chronicles these parallel symptoms and provides evidence suggesting GM1 as the crucial missing ganglioside. This idea correlates with the many previous studies demonstrating GM1 amelioration of parkinsonism in mouse and primate models of PD [9-13] as well as in PD patients $[14,15]$. In that light such treatment might eventually be viewed as a form of replacement therapy pending verification of the hypothesis that susceptible DA cells in PD suffer deficiency of GM1.

\section{Methods}

Animals and Behavioral tests

A breeding pair of heterozygotes with disrupted gene for GM2/GD2 synthase (C57BL/6 background), created by Dr. Richard Proia and coworkers [16] was provided as a gift by Dr. Ronald Schnaar (Johns Hopkins University School of Medicine). Animals were maintained in the University of Medicine and Dentistry of New Jersey Research Animal Facility with $12 \mathrm{~h}$ light/dark cycles. They were genotyped by PCR analysis as described [5]. All animal procedures were in accord with the guidelines of the UMDNJ Animal Care and Use Committee (IACUC).

Wild type (WT) and KO mice of both genders at 35 and 200 days of age (DOA) were used. To determine physical impairment, a grip-hanging test was employed in which the mouse clings with forepaws to a narrow horizontal rod positioned $50 \mathrm{~cm}$ above a pillow and hang time to fall is measured [17]; the mouse's tail is gently held by experimenter to prevent climbing with hind legs. Hang times in three consecutive trials, with rest intervals of $20 \mathrm{~min}$, were averaged. The second test, adhesive removal, was used to determine motor response to sensory stimulus [18]. A small piece of adhesive is applied to the snout and the time to removal by forepaw is recorded. Durations longer than $120 \mathrm{~s}$ were counted as $120 \mathrm{~s}$. Each animal was measured five times and the shortest three times were averaged. In rescue experiments, animals were injected intraperitoneally (IP) with GM1 $(30 \mathrm{mg} / \mathrm{kg})$, LIGA-20 $(2.5 \mathrm{mg} / \mathrm{kg})$ or balanced salt solution (BSS; Alcon, Fort Worth, TX) $3 \times /$ week over 5 weeks and then subjected to behavioral tests. GM1 and LIGA-20 were gifts from the Fidia Research Laboratories (Abano Terme, Italy). To test the rescue effect of L-dopa on impairment, KO mice were IP injected with L-dopa $(20 \mathrm{mg} / \mathrm{kg}$ ) plus carbidopa $(3 \mathrm{mg} / \mathrm{kg}$ ) in BSS and subjected to behavioral tests $3 \mathrm{~h}$ after injection; this was compared to test results before L-dopa administration. Statistical analysis was via two-tailed Student's t test. After behavior tests, mice were perfused (see below) and the frozen brains stored prior to histochemical and biochemical assays.

\section{Histochemical Analyses}

Animals were subjected to cardiac perfusion with phosphate buffered saline (PBS) followed by $4 \%$ parafomaldehyde in PBS. The brains were fixed overnight or longer in $4 \%$ paraformaldehyde followed by transfer to $30 \%$ sucrose (cryoprotection) in PBS and storage at $4^{\circ} \mathrm{C}$. Coronal frozen sections $(25 \mu \mathrm{m})$ were cut from the midbrain and stained with CtxB-FITC $(1 \mu \mathrm{g} / \mathrm{ml}$; Sigma; 
St. Louis, MO) and anti-tyrosine hydroxylase $(\mathrm{TH})$ antibody (Ab) (Millipore; Billerica, MA; 1:1000) plus 2nd Ab linked to Texas red. Other sections were stained with above anti-TH Ab plus Texas red 2nd Ab and anti-a-syn Ab (BD Science, 1:2000) plus 2nd Ab linked to FITC. Immunofluorescence in the SNpc region was photographed with 40X objective lens. Stereological analysis was carried out on the SNpc and ventral tegmental area (VTA) of brains from three KO treated with BSS, three KO mice treated with LIGA-20 $(2.5 \mathrm{mg} / \mathrm{kg})$, and three WT brains; this was done at the Rutgers University Molecular Histology Center (Dr. Eric Richfield; http://eohsi.rutgers.edu/mhc/). In preparation the brains were perfused, fixed and cryoprotected as above. Using the above anti-TH $\mathrm{Ab}$ with Texas red 2nd Ab, the total number of $\mathrm{TH}+$ neurons in the SNpc and VTA were counted using the optical fractionator and previously described counting criteria $[19,20]$. The right and left sides were counted in each brain. Regions of interest (ROI) were outlined at low magnification (4X objective) and sampled at high magnification (100X oil immersion objective) using StereoInvestigator (MicroBrightField, VT). ROI were selected based on literature descriptions and their consistent visual identification at 4X. For the area sampling fraction (asf) a sampling frame of size of $55 \times 55 \mu \mathrm{m}\left(3,025 \mu^{2}\right)$ and a grid area of $123 \times 123 \mu \mathrm{m}\left(15,129 \mu \mathrm{m}^{2}\right)$ yielding an asf of $20 \%$ were employed. All choices were made to obtain sufficient precision for $\mathrm{TH}+$ neuron counts in the SNpc and VTA.

\section{Immunoblot Assay for Alpha-synuclein}

Freshly collected brains from PBS perfused mice were employed and the midbrain cut into $250 \mu \mathrm{m}$ coronal sections with a vibratome sectioning system in cold PBS. The entire SN region, including compact and reticulum, was isolated with a dissecting microscope. The pooled sections were extracted with Cell Lysis Buffer (Cell Signaling, Danvers, MA) and aliquots containing $20 \mu \mathrm{g}$ protein were resolved with SDS-PAGE on a $4-15 \%$ gradient gel (Bio-Rad, Hercules, CA). After transfer to PVDF membrane, proteins were blotted with anti-a-syn antibody (1:1000; Santa Cruz Biotec; Sanda Cruz, CA) followed by 2nd $\mathrm{Ab}$ linked to horseradish peroxidase (HRP). Protein bands were revealed by ECL reagent (Amersham; Piscataway, NJ) on film. Anti-actin $\mathrm{Ab}$ (Sigma) was run in parallel for loading control. The optical density of actin and a-syn polymer (ranging from 34 to $170 \mathrm{Kd}$ ) blots was scanned and quantified by AlphaEase FC imaging system (Alpha Innotech, San Leandro, CA). Three brains in each group were assayed, the data normalized with respect to actin and statistically analyzed with the Student's t-test.
Neurochemistry

For DA assay, striatal samples prepared as above were each homogenized and sonicated in $0.7 \mathrm{ml}$ cold $0.4 \mathrm{~N}$ perchloric acid containing $70 \mathrm{ng}$ dihydroxybenzylamine as internal standard for $20 \mathrm{~min}$. This was centrifuged for $20 \mathrm{~min}$ at $16,000 \mathrm{~g}$, the supernatant filtered through a Millex-GV syringe filter $(0.22 \mu \mathrm{m}$; Millipore $)$ and the filtrate stored at $-20^{\circ} \mathrm{C}$ prior to analysis. One hundred $\mu \mathrm{l}$ was applied to a DIONEX ICS-3000 HPLC system with a 5- $\mu \mathrm{m}$ C8 Acclaim 120 column and electrochemical detector $(0.7 \mathrm{~V})$. Concentrations of DA and dihydroxyphenylacetic acid (DOPAC) were determined from peak areas adjusted to aliquot size, internal standard, and protein content. Also assayed by HPLC was serotonin (5-HT) and its metabolite, 5-hydroxyindole acetic acid (5-HIAA). Protein content was determined by the Lowry method following digestion of the $\mathrm{HClO}_{4}$ pellet several hrs in $\mathrm{NaOH} / \mathrm{SDS}$ [21].

\section{Results}

The impaired movement of KO mice that became more evident with age was quantified by the two methods described above. Such mice at 200 DOA retained their forepaw grasp on a horizontal bar for $20 \mathrm{~s}$ or less in contrast to WT mice which maintained their grasp for $150 \mathrm{~s}$ or more (Fig. 1 $\mathrm{A} b$ ). Surprisingly, the same was true of relatively young KO mice, 35 DOA (Fig. 1A $a$ ). Grip duration was fully restored to the latter mice by serial IP injections $(3 \times /$ week $)$ of LIGA-20 over the 5 week period, while grip duration was significantly improved by LIGA-20, though less dramatically, for the older mice. GM1 similarly administered to the younger KO mice had relatively little effect. The second impairment test, determining motor response to sensory stimulus by measuring time for removal of adhesive irritant from the snout, gave similar results: older $\mathrm{KO}$ mice required $60 \mathrm{~s}$ in contrast to WT time of $\sim 5 \mathrm{~s}$ (Fig. 1B $b$ ). The younger KO mice effected removal in $\sim 30 \mathrm{~s}$, significantly more than the $\sim 2 \mathrm{~s}$ required by the younger WT mice. As before, GM1 administered to the younger $\mathrm{KO}$ mice had virtually no effect. In both tests the ameliorative effect of LIGA-20 rose gradually over the 5 weeks, reaching a plateau at $\sim 3$ weeks (not shown).

Comparison of $\mathrm{TH}$-expressing neurons in $\mathrm{SNpc}$ of $\mathrm{KO}$ versus WT brains of $\sim 200$ day old mice suggested significant deficiency in the mutant (Fig. 2). Tyrosine hydroxylase (TH), an enzyme that catalyzes the first step in conversion of tyrosine to DA, is a marker for DA neurons. This was quantified by unbiased stereology employing anti$\mathrm{TH} \mathrm{Ab}$ to count DA neurons in the SNpc and VTA. Decrease in TH-expressing neurons was significant in the 
Fig. 1 Movement impairment in $\mathrm{KO}$ mice. Mice at $35(\mathbf{A} a$, $\mathbf{B} a)$ and $200(\mathbf{A} b, \mathbf{B} b)$ days of age were IP injected with GM1, LIGA20 or BSS for 5 weeks.

They were subjected to the griphanging (A) and adhesive removal $(\mathbf{B})$ tests. ()$=\mathrm{n}$. Data are average \pm SEM. $* *$ and *** represent $P<0.01$ and 0.001 compared to BSS-treated WT with Student's two-tailed t test

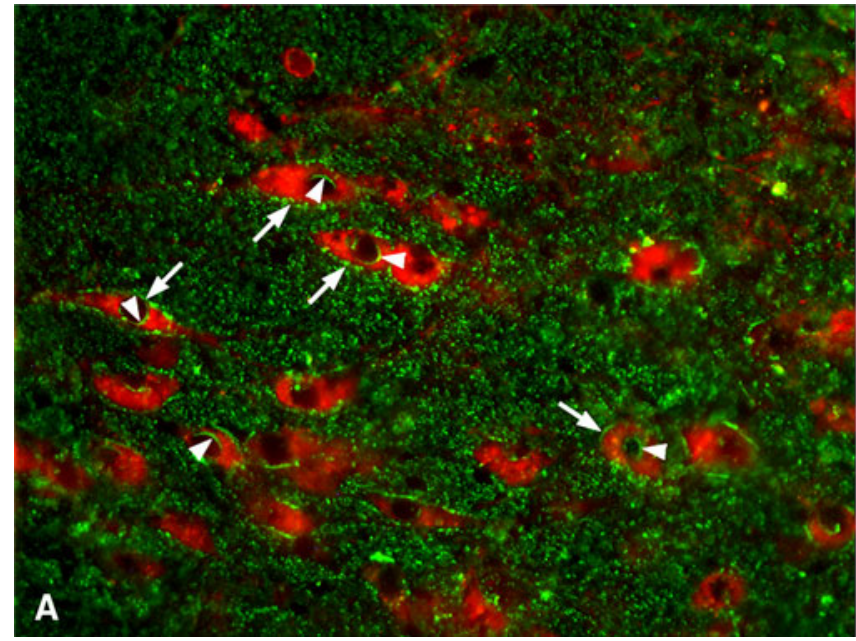

Fig. 2 Degeneration of $\mathrm{TH}+$ neurons in $\mathrm{SNpc}$ of $\mathrm{KO}$ mice. Brain sections containing SNpc from 200 day old WT (A) and KO (B) mice were stained with anti-TH antibody (2nd Ab with Texas red) and CtxB-FITC for GM1 (green), showing reduced number of

SNpc, and although the VTA showed a decrease this did not reach significance (Fig. 3). These changes accord with the significant loss of DA neurons in the $\mathrm{SNpc}$ and relative sparing of DA neurons in the VTA reported for murine models of PD [22]. Treatment of the KO mice with LIGA20 over the 5 week period elevated $\mathrm{TH}+$ neurons in the $\mathrm{SNpc}$ to the point where the $\mathrm{TH}+$ count in SNpc of LIGA-
BSS

GM1 LIGA20
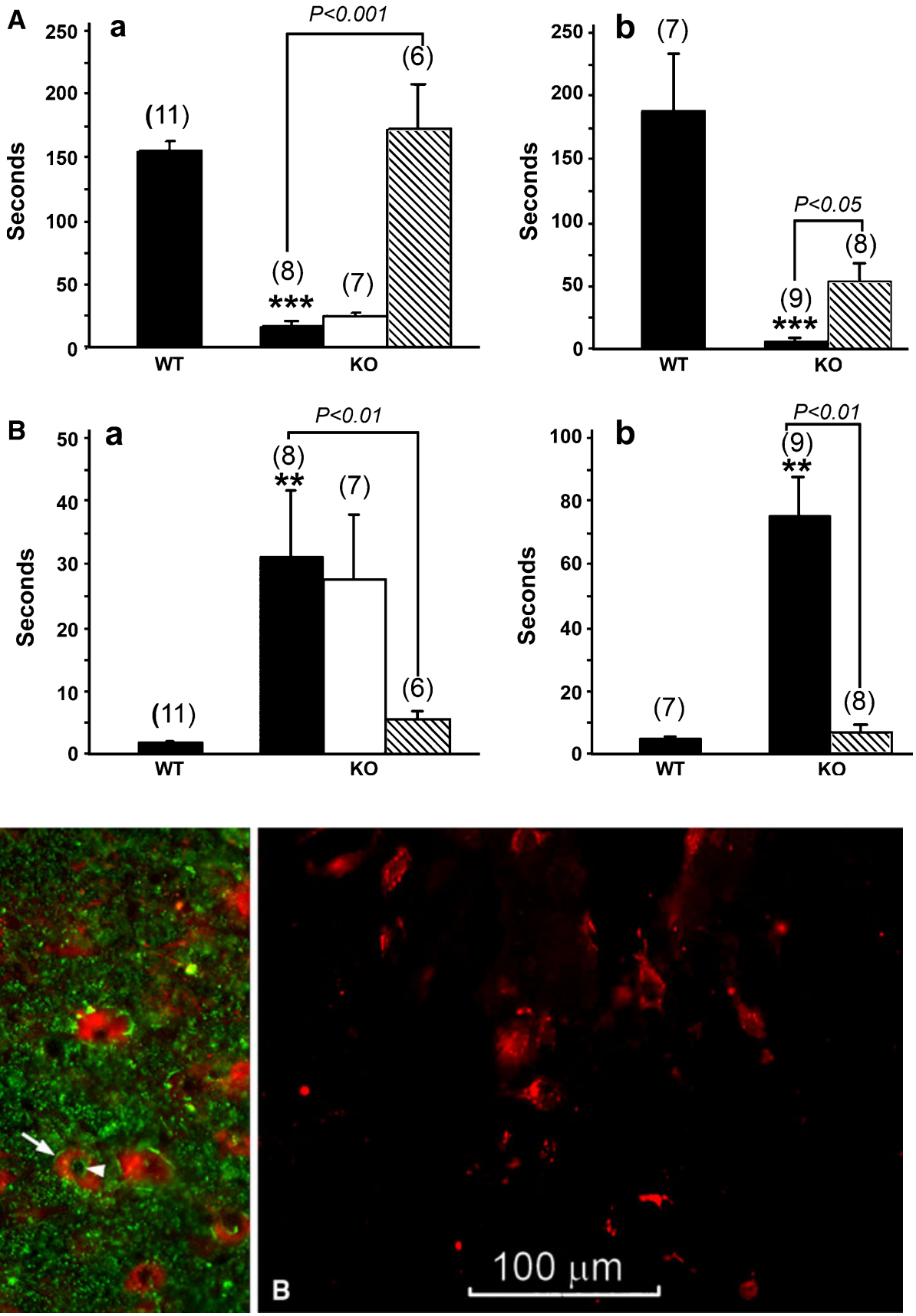

$\mathrm{TH}+$ neurons in $\mathrm{KO}$ mice. Expression of GM1 in WT TH+ neurons is indicated by arrows (plasma membrane) and arrowheads (nuclear membrane). Photographed with 40X objective lens

20-treated mice was not significantly different from WT $(P=0.059)$, even though the difference between $\mathrm{KO}$ and KO + LIGA-20 did not reach significance.

Alpha synuclein expression was greatly elevated in $\mathrm{SNpc}$ of KO brain, as revealed by immunocytochemistry; 5 weeks of LIGA-20 treatment attenuated a-syn levels while restoring much of the depleted $\mathrm{TH}$ expression 


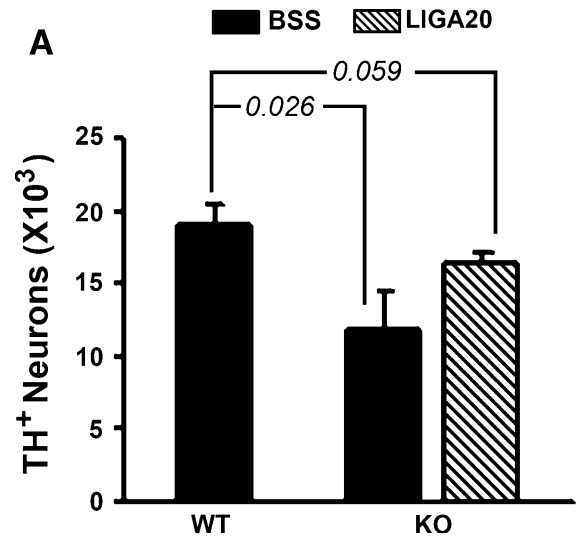

Fig. 3 Stereological analysis. WT and KO mice (200 days old) were IP injected with LIGA-20 or BSS for 5 weeks. Brain sections were immunostained with anti-TH as shown in Fig. 2 and subjected to stereological analysis. Two regions, $\mathrm{SNpc}$ (A) and VTA (B), containing $\mathrm{TH}+$ neurons were counted. The data are average $( \pm$ SEM) of 3 animals in each group $(n=3)$. Significant decrease in DA neurons of SNpc but not VTA was indicated by Student's two-

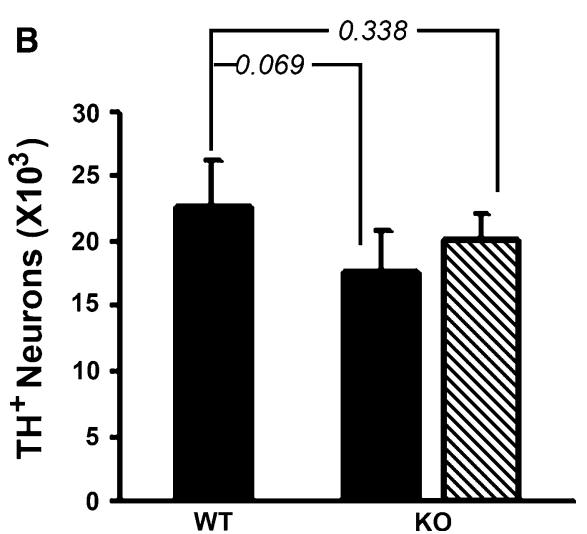

tailed $t$ test. These changes accord with the significant loss of DA neurons in the SNpc and relative sparing of DA neurons in the VTA reported for PD and murine models of PD [22]. Although the difference between $\mathrm{KO}$ and $\mathrm{KO}+$ LIGA-20 did not reach significance, the treatment rendered the difference between WT and KO + LIGA-20 insignificant
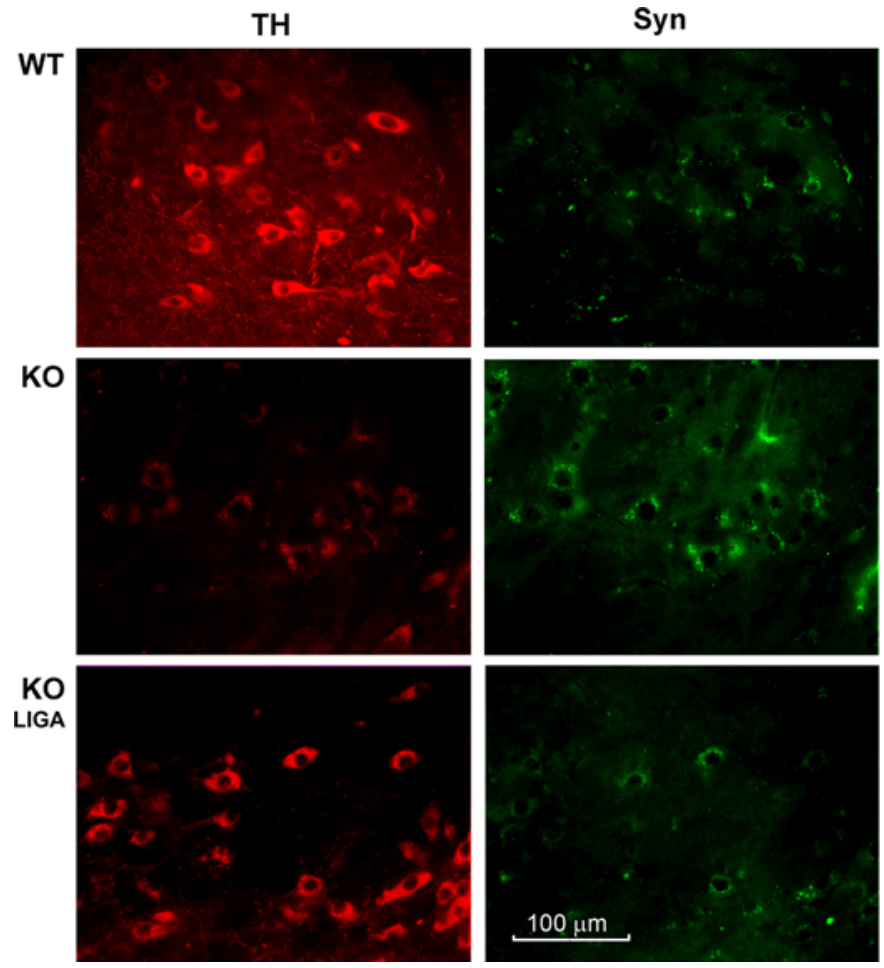
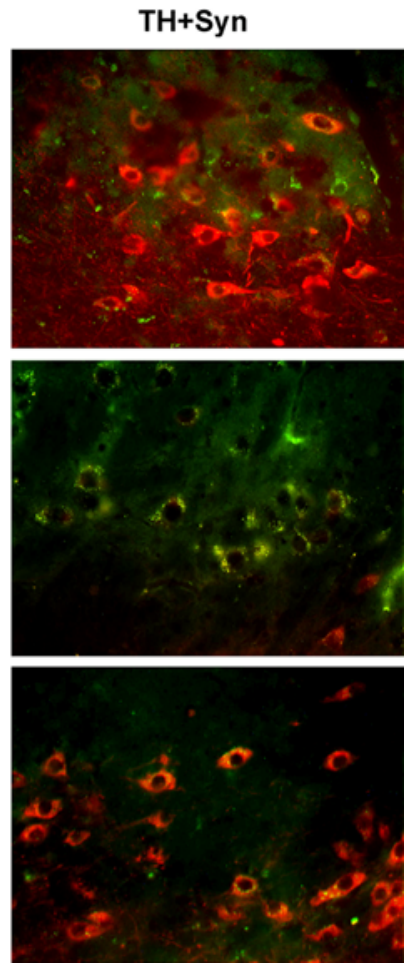

Fig. 4 Accumulation of a-syn in $\mathrm{TH}+$ neurons. Brain sections were co-stained with anti-TH (2nd Ab with Texas red) and anti-a-syn (2nd $\mathrm{Ab}$ with FITC), showing reduced $\mathrm{TH}+$ neurons and aggregated a-syn

(Fig. 4). Quantitative verification of a-syn elevation was obtained by Western blot analysis, which also indicated aggregation by marked increase of higher molecular weight bands at 34- and $170 \mathrm{kDa}$ as well as less dense bands in between; this applied to mice 200 DOA (Fig. 5A $b$ ) as well as younger mice at 35 DOA (Fig. 5A $a$ ). Densitometric quantification revealed significant reduction of aggregated in remaining $\mathrm{TH}+$ neurons in $\mathrm{KO}$ mouse. IP injection of $\mathrm{KO}$ mouse with LIGA-20 for 5 weeks attenuated a-syn accumulation while rescuing $\mathrm{TH}+$ neurons

forms of a-syn following 5 weeks of LIGA-20 treatment of both age groups, in contrast to GM1 which produced no significant reduction (Fig. 5B).

Dopamine levels in the striatum, measured as described by HPLC, were significantly reduced in $\mathrm{KO}$ mice compared to WT, as was also observed for DOPAC, a principal DA metabolite (Fig. 6a). Serotonin, another neurotransmitter in 
A

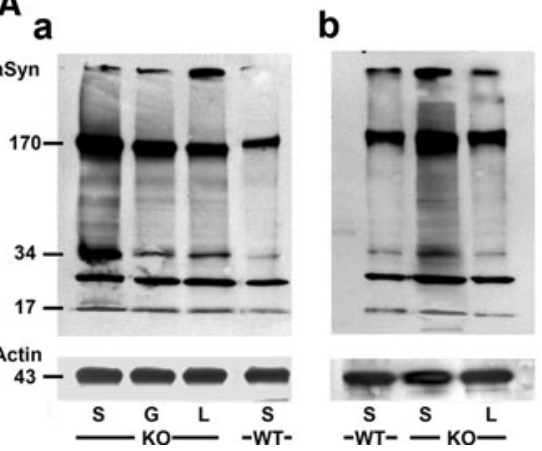

B

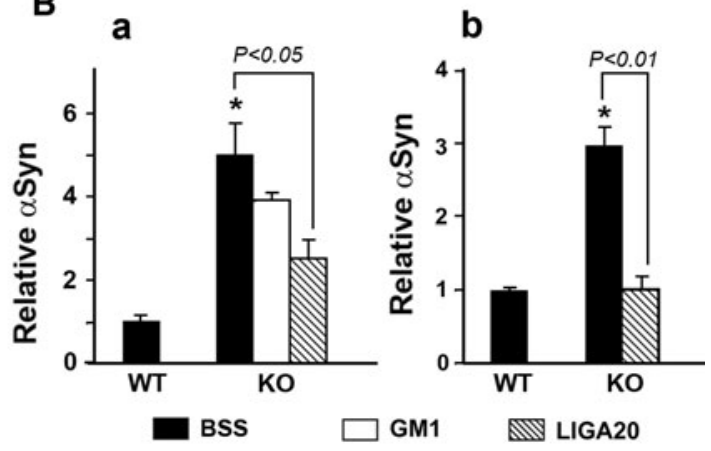

Fig. 5 Immunoblot analysis for a-syn accumulation. WT and KO mice at $35(\mathbf{A} a, \mathbf{B} a)$ and $200(\mathbf{A} b, \mathbf{B} b)$ days of age were treated with BSS, GM1 (G), or LIGA-20 (L). Brain tissue of SN regions was micro-dissected, and subjected to immuno-blotting for a-syn. Housekeeping protein actin was run in parallel for loading control. A Blot images showing polymerization of a-syn ranging form $34-$ to $170 \mathrm{kD}$.
B Densitometry quantification of a-syn polymers. Data are mean \pm SEM from 3 mice in each group $(n=3)$. Student's two-tailed t test was employed. $* P<0.01$ versus BSS-treated WT. The results show enhanced aggregation of a-syn in $\mathrm{KO}$, which is significantly reduce by LIGA-20 but not GM1

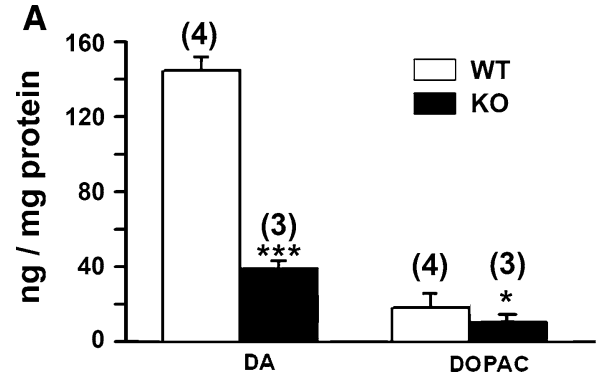

Fig. 6 Biochemical analyses. Dissected striata were extracted with $0.4 \mathrm{~N} \mathrm{HClO}_{4}$, spiked with dihydroxybenzylamine as internal standard and subjected to HPLC. (A) Striatal DA and DOPAC, that were significantly reduced in the KO; (B) 5-HT and 5-HIAA, that were not

the striatum, and 5-HIAA, its metabolite, were moderately reduced by an amount that did not reach significance (Fig. 6b). To test whether the movement disorders were due to depleted DA, KO mice were administered L-dopa as described. The animals thus treated showed highly significant recuperation from physical impairment as determined by both tests (Fig. 7). Mice in both age groups showed approximately equal rescue from physical impairment in both tests.

\section{Discussion}

Parkinson's disease is the second most prevalent late-onset neurodegenerative disorder that affects nearly $1 \%$ of the global population aged 65 and older. It is a progressive neurodegenerative disease characterized by resting tremor, postural rigidity, bradykinesia, autonomic instability and in its later stages by cognitive and emotional disorders [23, 24]. A principal feature is loss of pigmented DA neurons in the SNpc that project to the striatum, resulting in DA

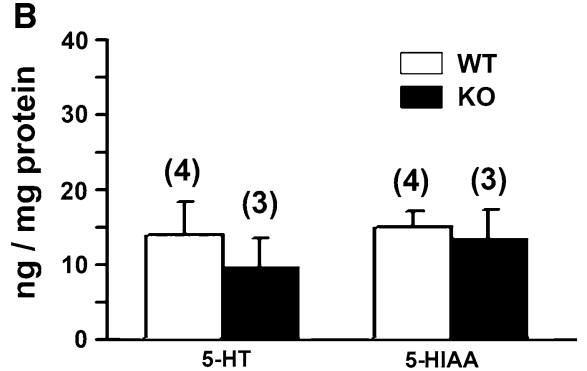

significantly reduced. Data are averages \pm SEM; \# of animals indicated in (). Statistical significance was determined by Student's two-tailed t test: $*$ and $* * *$ represent $P<0.05$ and 0.001 , respectively

deficit and aberrations in the activity of the neural circuits within the basal ganglia that regulate movement. Cytosolic accumulation of Lewy bodies that contain aggregated a-syn is an additional hallmark of the disease [25]. The large majority of PD cases have been described as sporadic, the remainder as familial based on a variety of genetic mutations. Symptomatic treatments of the motor features are in clinical use but no neuroprotective treatment to prevent progressive loss of DA neurons has yet become available.

This study has provided evidence for the presence of key features of parkinsonism in genetically modified mice with disrupted gene for Galgt1 (GalNAcT; GM2/GD2 synthase). This included behavioral, histopathological, and biochemical parameters that are the defining symptoms of PD. These findings thus amplify and extend previous observations of behavioral and cellular pathologies of these mutants, which included progressive behavioral neuropathies involving deficits in reflexes, strength, coordination, balance, and gait [4]. A morphological study revealed axonal degeneration and decreased central myelination [3]. These earlier reports thus indicated a variety of 

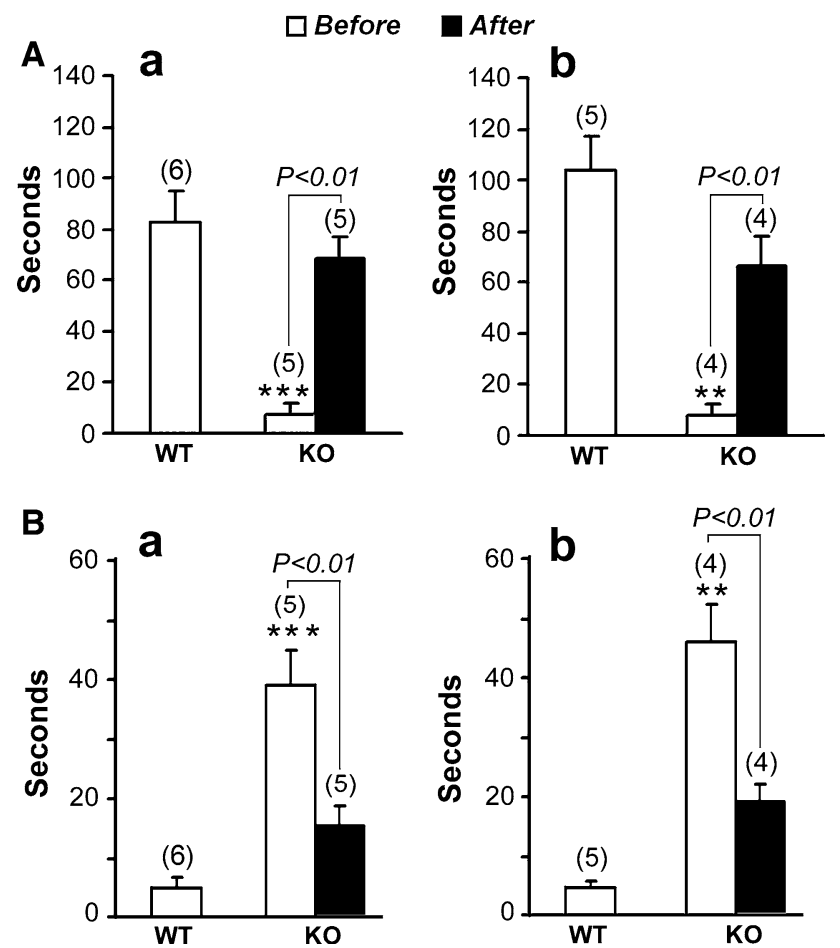

Fig. 7 Effect of L-dopa on physical impairment. Mice at 35 (A $a$, $\mathbf{B} a)$ and $200(\mathbf{A} b, \mathbf{B} b)$ days of age were IP injected with L-dopa $(20 \mathrm{mg} / \mathrm{kg}$ ) and carbidopa $(3 \mathrm{mg} / \mathrm{kg}$ ). Behavior tests, grip-hanging (A) and adhesive removal (B), were performed before and $3 \mathrm{~h}$ after injection. Data are average \pm SEM; ()$=\mathrm{n}$. Two-tailed Student's t test was used for statistical analysis. ** and *** represent $P<0.01$ and 0.001 respectively compared to WT before L-dopa treatment

neuropathies and neuropathologies attendant to these mutant mice while the present study has elucidated PD-like symptoms not previously reported. Disruption of this gene for a key enzyme in synthesis of GM2 results in ablation of that molelcule and the entire gangliotetraose series [3, 16] which comprise $>90 \%$ of the complex gangliosides of brain; corresponding elevations of GM3 and GD3 have been observed [5, 26].

We hypothesize that much of the PD-specific symptomatology observed here derives from the GM1 deficit, based in part on the rescue effects of LIGA-20. This GM1 analog, developed by Costa and coworkers [27], contains the same oligosaccharide chain as GM1 but a modified hydrophobic moiety (replacement of ceramide stearoyl by dichloroacetyl) that induces membrane permeability. The latter property has been affirmed both in vitro with primary neurons [28] and in vivo with CNS neurons of ganglioganglioside-deficient mice suffering enhanced kainateinduced seizures [6]. LIGA-20 proved more potent than GM1 in partially restoring depleted DA levels in MPTPtreated mice [11] and, significantly, was able to accomplish this via oral administration [29]. These manifestations of LIGA-20 efficacy, believed to derive from its membrane permeability, result in enhanced ability to cross the blood brain barrier and the neuronal plasma membrane. When applied to cells or mice deficient in GM1 it thus serves as replacement for the missing ganglioside in both the plasma membrane and intracellular sites where GM1 has functional roles. Intracellulaar loci include the nuclear $\mathrm{Na}^{+} /$ $\mathrm{Ca}^{2+}$ exchanger which is potentiated by GM1 [30,31], the autophagy pathway including promotion of lysosomal integrity [32], and a-syn which requires GM1 association to prevent fibrillation and maintenance of helical conformation [33]. Long term $\mathrm{Ca}^{2+}$ dysregulation in the DA neurons of the SNpc, associated with their autonomous pacemaker activity and resultant mitochondrial impairment, has been suggested as a major contributor to the selective vulnerability of those neurons over time [34]. An additional reason for ascribing primacy to GM1 is the finding that knockout mice with disrupted GD3 synthase, resulting in deletion of all b- and c-series and retention of a-series gangliosides, showed virtually intact nervous system morphology with no apparent abnormal behavior despite some aberrations in pain perception and nerve regeneration [35, 36]. GD1a, the other prominent ganglioside of the a-series, often functions as metabolic precursor to GM1 through the action of membrane-bound sialidase [37, 38]. The complexity of ganglioside changes that occur in the Galgt1 mutant and the uncertainty as to which GM1 functions are efficiently restored by LIGA-20 require caution at this stage in ascribing a primary role to GM1 deficiency in relation to parkinsonism. However, the results of this and the other mentioned studies point to that conclusion.

Additional evidence of a key role for $\mathrm{Ca}^{2+}$ dysregulation in $\mathrm{PD}$ is the finding that elevated $\mathrm{Ca}^{2+}$ promoted a-syn aggregation in $1321 \mathrm{~N} 1$ cells expressing an a-syn-GFP construct [39]. Alpha synuclein in aggregated form, together with ubiquitin, is a prominent component of Lewy bodies which are pathological hallmarks of PD. Lewy bodies as such are not usually found in rodent models of PD, but inclusion bodies staining for a-syn and ubiquitin have been observed [40]. The present study obtained Western blot evidence for a-syn aggregation in the prominence of higher molecular weight bands between 34- and 170- $\mathrm{kDa}$ in $\mathrm{KO}$ striatum compared to WT (Fig. 5). As shown, the densities of such bands were noticeably diminished by LIGA-20 treatment of the KO mice. Significantly, a-syn aggregation was inhibited specifically by GM1 which promoted its alpha-helical structure [33].

A randomized double blind placebo controlled study reported that GM1-treated PD patients showed significant improvements on Unified Parkinson's Disease Rating Scale (UPDRS) motor scores and performance of timed motor tasks, compared to baseline performance [14]. Subsequently a 5 year open study revealed that patients using GM1 had lower UPDRS motor scores than at baseline [15]. These are interesting findings in view of preliminary results 
in our lab showing a marked deficiency of GM1 in DA neurons of the SNpc of PD patients, compared to agematched controls. This suggests that applied GM1 may be functioning as a form of replacement therapy to the limited extent it is able to enter the brain of PD patients. This leads to the further suggestion that membrane permeable derivatives of GM1 may prove more efficacious in preserving DA neuronal viability and alleviating PD pathology.

Acknowledgments This work was supported by NIH grant 2 RO1 NS33912.

It is a pleasure to contribute to this special issue of Neurochemical Research honoring Dr. Robert Yu for his many seminal contributions to the field of Neurochemistry. His studies on the biochemistry, cell biology, and pathophysiology of glycosphingolipids have been well recognized and honored over the years. Bob was my first postdoc (and his first such experience) more than a few years ago, coming from the lab of Herbert Carter, an iconic sphingolipid pioneer at the University of Illinois. Herbert responded to my inquiry with the affirmation that Bob was indeed a promising young neuroscientist who would likely contribute to my program. That proved quite a good prophecy; everyone should be so lucky as to have someone like Bob as their first posdoc. Those years were memorable for the quality and quantity of the work he produced as well the beginning of a life long friendship. I'm convinced there are many more miles to go in terms of Bob's contributions to neuroscience.

Open Access This article is distributed under the terms of the Creative Commons Attribution Noncommercial License which permits any noncommercial use, distribution, and reproduction in any medium, provided the original author(s) and source are credited.

\section{References}

1. Allende ML, Proia RL (2002) Lubricating cell signaling pathways with gangliosides. Current Opinion in Struct Biol 12:587-592

2. Takamiya K, Yamamoto A, Furukawa K et al (1996) Mice with disrupted GM2/GD2 synthase gene lack complex gangliosides but exhibit only subtle defects in their nervous system. Proc Nat Acad Sc USA 93:10662-10667

3. Sheikh KA, Sun J, Liu Y et al (1999) Mice lacking complex gangliosides develop Wallerian degeneration and myelination defects. Proc Nat Acad Sci USA 96:7532-7537

4. Chiavegatto S, Sun J, Nelson RJ et al (2000) A functional role for complex gangliosides: motor deficits in GM2/GD2 synthase knockout mice. Exp Neurol 166:227-234

5. Wu G, Xie X, Lu Z-H et al (2001) Cerebellar neurons lacking complex gangliosides degenerate in the presence of depolarizing levels of potassium. Proc Natl Acad Sci USA 98:307-312

6. Wu G, Lu Z-H, Wang J et al (2005) Enhanced susceptibility to kainate-induced seizures, neuronal apoptosis, and death in mice lacking gangliotetraose gangliosides: protection with LIGA 20, a membrane-permeant analog of GM1. J Neurosci 25:11014-11022

7. Braak H, Del Tredici K, Rub U et al (2003) Staging of brain pathology related to sporadic Parkinson's disease. Neurobiol Aging 24:197-211

8. Meredith GE, Sonsalla PK, Chesselet M-F (2008) Animal models of Parkinson's disease progression. Acta Neuropathol 115:385398

9. Hadjiconstantinou M, Rossetti ZL, Paxton RC et al (1986) Administration of GM1 ganglioside restores the dopamine content in striatum after chronic treatment with MPTP. Neuropharm 25:1075-1077

10. Schneider JS, Kean A, DiStefano L (1995) GM1 ganglioside rescues substantia nigra pars compacta neurons and increases DA synthesis in residual nigrostriatal dopaminergic neurons in MPTP-treated mice. J Neurosci Res 42:117-123

11. Schneider JS, DiStefano L (1995) Response of the damaged dopamine system to GM1 and semisynthetic gangliosides: effects of dose and extent of lesion. Neuropharm 34:489-493

12. Hadjiconstantinou M, Mariani AP, Neff NH (1989) GM1 ganglioside-induced recovery of nigrostriatal dopaminergic neurons after MPTP: an immunohistochemical study. Brain Res 484:297-303

13. Pope-Coleman A, Schneider JS (1998) Effects of chronic GM1 ganglioside treatment on cognitive and motor deficits in a slowly progressing model of Parkinsonism in non-human primates. Restorative Neurol Neurosci 12:255-266

14. Schneider JS, Roeltgen DP, Mancall EL (1998) Parkinson's disease: improved function with GM1 ganglioside treatment in a randomized placebo-controlled study. Neurology 50:1630-1636

15. Schneider JS, Sendek S, Daskalakis C et al (2010) GM1 ganglioside in Parkinson's disease: results of a five year open study. J Neurol Sciences 292:45-51

16. Liu Y, Wada R, Kawai H et al (1999) A genetic model of substrate deprivation therapy for a glycosphingolipid storage disorder. J Clin Invest 103:497-505

17. Sedelis M, Hofele K, Auburger GW et al (2000) MPTP susceptibility in the mouse: behavioral, neurochemical, and histological analysis of gender and strain differences. Behav Genet 30:171-182

18. Lu XH, Fleming SM, Meurers B et al (2009) Bacterial artificial chromosome transgenic mice expressing a truncated mutant parkin exhibit age-dependent hypokinetic motor deficits, dopaminergic neuron degeneration, and accumulation of proteinase K-resistant alpha-synuclein. J Neurosci 29:1962-1976

19. Prasad K, Richfield EK (2008) Sporadic midbrain dopamine neuron abnormalities in laboratory mice. Neurobiol Disease 32:262-272

20. Prasad K, Richfield EK (2010) Number and nuclear morphology of $\mathrm{TH}+$ and $\mathrm{TH}-$ neurons in the mouse ventral midbrain using epifluorescence stereology. Exp Neurol 225:328-340

21. Lees M, Paxman S (1972) Lipid composition of the normal human brain: gray matter, white matter, and myelin. J Lipid Res 6:537-544

22. German DC, Manaye KF, Sonsalla PK, Brooks BA (1992) Midbrain dopaminergic cell loss in Parkinson's disease and MPTP-induced Parkinsonism: sparing of calbindin- $\mathrm{D}_{28 \mathrm{k}}$-containing cells. Ann NY Acad Sci 648:42-62

23. Fahn S (2006) Description of Parkinson's disease as a clinical syndrome. Ann NY Acad Sci 991:1-14

24. Jankovic J (2008) Parkinson's disease: clinical features and diagnosis. J Neurol Neurosurg Psych 79:368-376

25. Eriksen JL, Dawson TM, Dickson DW et al (2003) Caught in the act: alpha-synuclein is the culprit in Parkinson's disease. Neuron 40:453-456

26. Matsuda J, Vanier MT, Popa J et al (2006) GD3- and O-acetylated GD3-gangliosides in the GM2 synthase-deficient mouse brain and their immunohistochemical localization. Proc Jpn Acad Ser B 82:189-196

27. Manev H, Favaron M, Vicini S et al (1990) Glutamate-induced neuronal death in primary cultures of cerebellar granule cells: protection by synthetic derivatives of endogenous sphingolipids. J Pharmacol Exp Ther 252:419-427

28. Wu G, Lu Z-H, Xie X et al (2004) Susceptibility of cerebellar granule neurons from GM2/GD2 synthase-null mice to apoptosis induced by glutamate excitotoxicity and elevated $\mathrm{KCl}$ : rescue by GM1 and LIGA20. Glycoconj J 21:305-313 
29. Schneider JS, DiStefano L (1994) Oral administration of semisynthetic sphingolipids promotes recovery of striatal dopamine concentrations in a murine model of parkinsonism. Neurology 44:748-750

30. Xie X, Wu G, Lu Z-H et al (2002) Potentiation of a sodiumcalcium exchanger in the nuclear envelope by nuclear GM1 ganglioside. J Neurochem 81:1185-1195

31. Wu G, Xie X, Lu Z-H et al (2009) Sodium-calcium exchanger complexed with GM1 ganglioside in nuclear membrane transfers calcium from nucleoplasm to endoplasmic reticulum. Proc Natl Acad Sci USA 106:10829-10834

32. Wei J, Fujita M, Nakai M et al (2009) Protective role of endogenous gangliosides for lysosomal pathology in a cellular model of synucleinopathies. Amer J Pathol 174:1891-1909

33. Martinez Z, Zhu M, Han S et al (2007) GM1 specifically interacts with alpha-synuclein and inhibits fibrillation. Biochemistry 46:1868-1877

34. Chan CS, Gertler TS, Surmeier DJ (2009) Calcium homeostasis, selective vulnerability and Parkinson's disease. Trends Neurosci $32: 249-256$
35. Okada M, Itoh M, Haraguchi M et al (2002) b-series Ganglioside deficiency exhibits no definite changes in the neurogenesis and the sensitivity to Fas-mediated apoptosis but impairs regeneration of the lesioned hypoglossal nerve. J Biol Chem 277:1633-1636

36. Handa Y, Ozaki N, Honda T et al (2005) GD3 synthase gene knockout mice exhibit thermal hyperalgesia and mechanical allodynia but decreased response to formalin-induced prolonged noxious stimulation. Pain 117:271-279

37. Miyagi T, Wada T, Iwamatsu A et al (1999) Molecular cloning and characterization of plasma membrane-associated sialidase specific for gangliosides. J Biol Chem 274:5004-5011

38. Wang J, Wu G, Miyagi T, Lu Z-H, Ledeen RW (2009) Sialidase occurs in both membranes of the nuclear envelope and hydrolyzes endogenous GD1a. J Neurochem 111:547-554

39. Goodwin NS, Engelborghs Y, Pountney DL (2010) Raised calcium promotes $\alpha$-synuclein aggregate formation. Mol Cell Neurosci (2010 Dec 8) [Epub ahead of print]

40. Yazdani U, German DC, Liang C-L et al (2006) Rat model of Parkinson's disease: chronic central delivery of 1-methyl-4phenylpyridinium $\left(\mathrm{MPP}^{+}\right)$. Exp Neurol 200:172-183 